\title{
Structures and biological functions of zinc finger proteins and their roles in hepatocellular carcinoma
}

\author{
Xinxin $\mathrm{Li}^{1,2 \dagger}$, Mengzhen Han ${ }^{1,2 \dagger}$, Hongwei Zhang ${ }^{1,2 \dagger}$, Furong Liu ${ }^{1,2}$, Yonglong Pan ${ }^{1,2}$, Jinghan Zhu ${ }^{1,2}$, Zhibin Liao ${ }^{1,2^{*}}$ (D, \\ Xiaoping Chen ${ }^{1,2^{*}}$ and Bixiang Zhang ${ }^{1,2^{*}}$
}

\begin{abstract}
Zinc finger proteins are transcription factors with the finger domain, which plays a significant role in gene regulation. As the largest family of transcription factors in the human genome, zinc finger (ZNF) proteins are characterized by their different DNA binding motifs, such as $\mathrm{C} 2 \mathrm{H} 2$ and Gag knuckle. Different kinds of zinc finger motifs exhibit a wide variety of biological functions. Zinc finger proteins have been reported in various diseases, especially in several cancers. Hepatocellular carcinoma (HCC) is the third leading cause of cancer-associated death worldwide, especially in China. Most of HCC patients have suffered from hepatitis B virus (HBV) and hepatitis C virus $(\mathrm{HCV})$ injection for a long time. Although the surgical operation of HCC has been extremely developed, the prognosis of HCC is still very poor, and the underlying mechanisms in HCC tumorigenesis are still not completely understood. Here, we summarize multiple functions and recent research of zinc finger proteins in HCC tumorigenesis and progression. We also discuss the significance of zinc finger proteins in HCC diagnosis and prognostic evaluation.
\end{abstract}

Keywords: Zinc finger protein, Transcription factor, Hepatocellular carcinoma, Transcription regulation, Biological function

\section{Background}

Zinc finger proteins (ZFPs), which constitute the largest transcription factor family with finger-like DNA binding do- mains, play a significant role in multiple biological processes. ZFPs primarily function as transcription factors in tumorigenesis and tumor progression. Transcription factors (TFs) are proteins that play a vital role in complicated biological processes, such as metabolism, autophagy, apoptosis, immune responses, stemness

\footnotetext{
* Correspondence: zhibliao@hust.edu.cn; chenxpchenxp@163.com; bixiangzhang@163.com

${ }^{\dagger}$ Xinxin Li, Mengzhen Han and Hongwei Zhang contributed equally to this work.

${ }^{1}$ Hepatic Surgery Center, Tongji Hospital, Tongji Medical College, Huazhong University of Science and Technology, 1095 Jiefang Avenue, Wuhan 430030, China

Full list of author information is available at the end of the article
}

maintenance and differentiation. TFs regulate transcription of genes by recognizing or binding to DNA sequences directly [1,2]. So far, zinc finger motifs have been classified into eight different categories according to their main-chain conformation and secondary structure around their zinc-binding sites, including Cys2His2 $(\mathrm{C} 2 \mathrm{H} 2)$ like, Zn2/Cys6, Treble clef, Zinc ribbon, Gag knuckle, TAZ2 domain like, Zinc binding loops and Metallothionein $[3,4]$. In addition to these zinc motifs, ZFPs also contain several domains that play different roles in cell biological processes, including BTB (BroadComplex, Tramtrack, and Bric-a-brac), the Krüppel-Associated Box (KRAB) domain, SET domain and SCAN (SRE-ZBP, CTfin51, AW-1 and Number 18 cDNA) domain. Because of the diversity of zinc finger motifs and these domains, ZFPs can play different roles in gene 
regulation under various cellular environments and other stimuli.

Hepatocellular carcinoma (HCC) accounts for a major part of the global cancer category. It accounts for approximately $75-80 \%$ of primary liver cancer $[5,6]$. According to the Global online database of infectious diseases analysis, the incidence of liver cancer decreased in many Asian countries during $1978 \sim 2012$. Still, it rebounded in India, the United States and other European countries [6]. Since patients have no obvious clinical symptoms in the early stage of HCC, the early diagnosis of HCC becomes extremely difficult. Although there are many treatments, including surgical resection, chemotherapy, targeted therapy, the prognosis of liver cancer is still not optimistic. However, the numerous molecular mechanisms in HCC pathogenesis remain unclear. In recent years, studies about ZFPs functions in multiple cancers have been constantly emerging [7-14]. These studies offered promising treatments for malignancies, including HCC [15]. In this review, we will discuss ZFPs basic spatial structures and the complex mechanisms of ZFPs in HCC.

\section{Structures of zinc finger proteins BTB domain}

The BTB domain (also known as the POZ domain) is a multifaceted protein-protein interaction motif found in whole eukaryotes. At the same time, it has been reported in previous literature that some poxvirus proteins are similar to a part of ZFPs, like ZID, GagA and ZF5; this domain has been named as POZ (poxvirus and zinc finger) domain $[16,17]$. As a highly conserved structure, it engaged in multiple cellular functions, including transcription repression, cytoskeleton dynamics, tetramerization and gating of ion channels, and targeting proteins for ubiquitination [18-23]. The BTB domain consists of a cluster of five $\alpha$-helixes, one end covered by a short three-chain $\beta$-fold, which is compact and spherical [24]. In different BTB domains, their primary structure is less conservative, but their secondary structure is broadly similar. It has been reported that the BTB domain can be classified into four families: T1, Skp1, ElonginC, and BTB-ZF, but the details have not yet been worked out. Interestingly, the BTB domain in ZFPs can be homologous and heterogenous, or the BTB domain can recruit co-inhibitors of transcription. The function of proteins containing the BTB domain can be roughly divided into two categories: transcriptional inhibition and protein degradation, which are crucial for genes to function in cell development [25-27]..

\section{SCAN domain}

Scan domain, a highly conservative domain, consists of 84 amino acids rich in leucine residues, is also known as the leucine-rich region [28, 29]. To date, about 244 protein products containing the scan domain have been identified in the human genome, of which about 50 scan-containing transcription factors have been described. The scan domain has an amphipathic secondary structure that participates in protein-protein interaction, especially self-binding and mediated oligomerization [25, 30, 31]. Further studies of the domain have shown that it can interact with separated scan domains, such as scan domain protein 1 (SDP1), or with other family members with scan domains [32]. It is worth mentioning that this interaction is not universal but selective, suggesting that not all family members can form oligomerization. Interactions between different scan-containing transcription factors lead to various transcription activities. In addition, few proteins may have several special names depending on their domain. As can be seen from the NCBI gene database, the human ZSCAN (zinc finger and scan) transcription factor family members have a uniform name ranging from ZSCAN1 to ZSCAN54 [33].

\section{KRAB domain}

Krüppel-associated box (KRAB) domain-containing zinc finger proteins (KZFPs), which have been reported to exist only in quadrupeds. The human genome encodes approximately more than 350 KZFPS. In recent reports, KZFPs mainly inhibit transposable elements (TEs) by recruiting transcriptional regulators and heterochromatin formation and DNA methylation in embryonic stem (ES) cells $[34,35]$. The KRAB domain consists of 75 amino acids, and the domain is usually disconnected into two adjoining modules: A-box, which is mainly responsible for inhibiting activity by interacting with corepressors; and B-box, which is believed to augment the ability of repression of A-box through some undiscovered mechanisms [36-38]. Theoretically, the length of KRAB-ZFP should be enough to recognize longer DNA target sequences specifically, but in fact, the binding motif of KRAB-ZFP is often shorter than predicted. This implied that in KRAB-ZFP, different ZNF recognize different DNA motifs [39]. In addition, ZNF is not only involved in contacting with DNA but also can participate in other categorizes of interactions, such as interactions with RNA, or proteins [40-43]. A few ZFPs contain added domains, including BTB domain, SCAN domain, KRAB domain, SET domain, DUF3669 domain and $\mathrm{C} 2 \mathrm{H} 2$ motif. Regrettably, the precise function of the DUF3669 domain is still unclear (Fig. 1).

\section{SET domain}

The SET structural domain is widely found in eukaryotes and consists of approximately 130 amino acids and is named after the Drosophila proteins Suppressor of variegation 3-9 (Su (var)3-9), Enhancer of zeste (E(z)), and Trithorax (Trx). The biological behaviours in which 


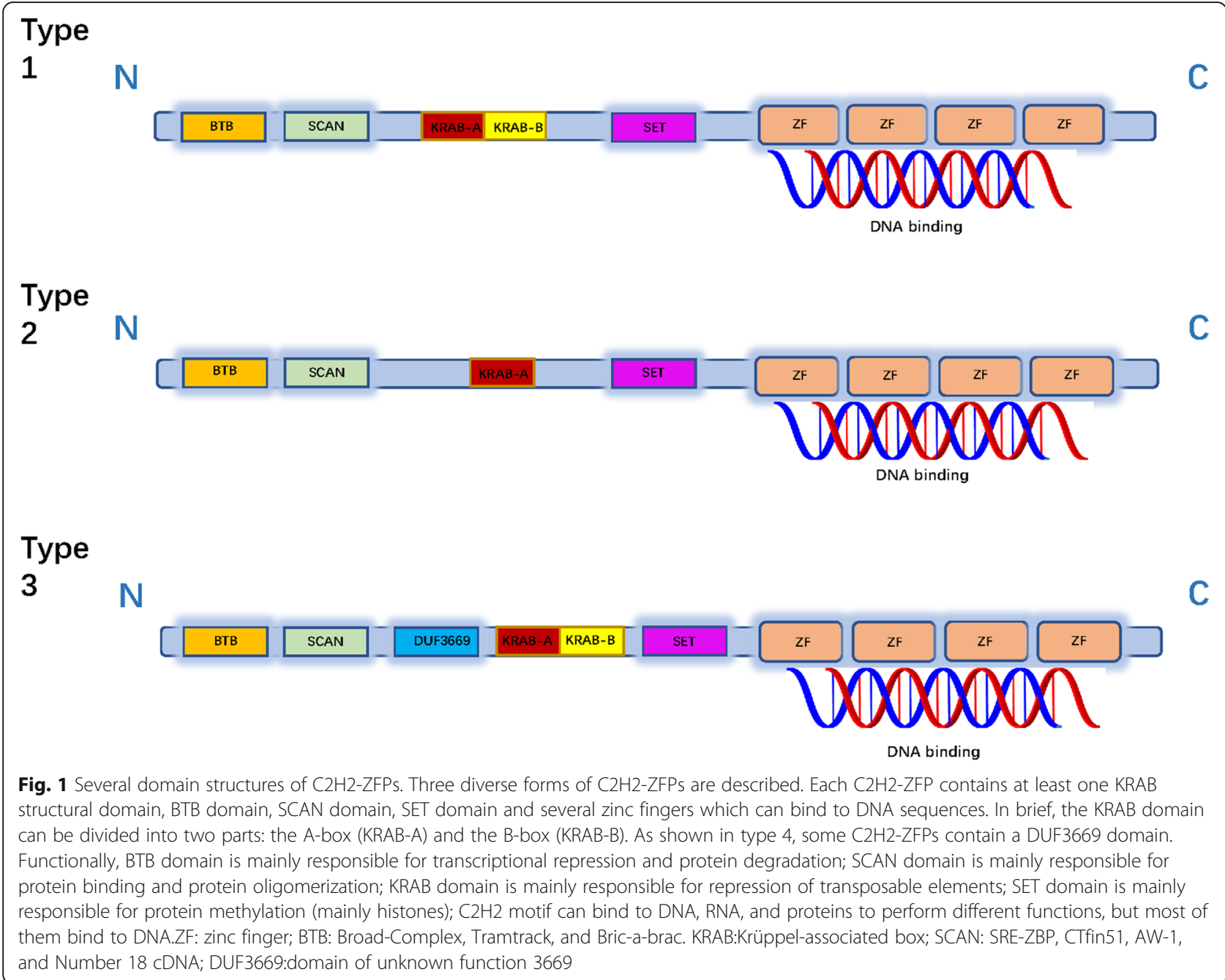

the SET structural domain is involved are primarily associated with the methylation of substrates. For example, many SET domain-containing proteins can mono-, di- or trimethylation of their lysine substrates using the cofactor S-adenosyl-L-methionine (SAM), these catalyzed targets include histones and many non-histone substrates. In addition, the SET domain does not usually exist as a stand-alone entity, and in many proteins, it co-exists with other protein structural domains and interacts with proteins that regulate its catalytic function $[44,45]$.

\section{$\mathrm{C} 2 \mathrm{H} 2$-zinc finger motif}

Among eight different groups of zinc fingers, the most classical zinc finger is the $\mathrm{C} 2 \mathrm{H} 2$-like finger [3]. As the most prevalent motif in ZFPs, over $5000 \mathrm{C} 2 \mathrm{H} 2$-like fingers have been encoded by the human genome [46]. The zinc finger structure is generally located at the Cterminus of the ZFPs. The consensus sequence for
$\mathrm{C} 2 \mathrm{H} 2$ zinc fingers is CX2CX3FX5LX2HX3H, which contains conservative hydrophobic residues wrapped in hydrophobic cores except for its two cysteines and two histidine residues. These conservative amino acids and a characteristic structure is consisting of a two-stranded antiparallel $\beta$-sheet and an $\alpha$-helix [47]. It has been suggested in the article that an individual zinc finger motif binds an adjacent three-nucleotide subsequence, maybe three to five, and a $\mathrm{C} 2 \mathrm{H} 2$-zinc finger domain can be specified to a range of three base pair (3 bp) targets $[48,49]$.

$\mathrm{C} 2 \mathrm{H} 2$-type ZFPs generally contain added anatomic domains, such as BTB (Broad-Complex, Tramtrack, and Bric-a-brac), the Krüppel-Associated Box (KRAB) domain, SET domain and SCAN (SRE-ZBP, CTfin51, AW1 and Number 18 cDNA) domain [40]. These structures regulate immune response, cell differentiation and embryonic development at the transcription and translation level through specifically binding to the target molecule DNA, RNA, DNA-RNA sequence, and binding to itself 
or other ZFPs [48]. For instance, ZEB1 can actuate transcription through binding to coactivators, such as p300 and P/CAF $[50,51]$.

\section{Comparison of the functions between these structural domains}

The domains of ZFPs are not only diverse, but the functions of these domains are also very distinct. For example, although both the BTB domain and the SCAN domain can bind to the protein, but the BTB domain mostly inhibits the transcriptional activity of the target gene by recruiting transcription co-repressors, while the SCAN domain causes oligomerization of target proteins through its specific binding [27, 31]. In addition, KZFPs can inhibit transposable elements through DNA methylation, while SET domains that have different substrates are through protein methylation to play its catalytic role $[34,44]$. In a word, various C2H2-type ZFPs contain different types of the above-mentioned domains, and these ZFPs with different functions play a significant role in in cell biological processes.

\section{Biological functions of zinc finger proteins}

Among the numerous biological functions of ZFPs, transcription regulation occupies a highly prominent position. ZFP relies on the domain-containing zinc finger in one segment to bind to the promoter region of the target gene and act as a transcription enhancer or transcription inhibitor. In addition to transcriptional regulation, ZFPs can induce protein-protein interactions, bind to RNA, and interact with proteins and RNAs in the meantime [52-55].

\section{Transcription regulation}

As the most prominent role of ZFPs, the functions of transcriptional regulation are mainly reflected in both transcriptional promotion and transcriptional repression. It has been recently reported that ZEB1 (Zinc finger Ebox binding homeobox 1) can bind to the HDGF (hepatoma-derived growth factor) promoter to stimulate HDGF transcription in EC (endometrial carcinoma) cells [56]. Another example on the contrary, ZNF322A, a $\mathrm{C} 2 \mathrm{H} 2$ zinc finger transcription factor, can directly bind and recruit histone deacetylation enzyme 3 to the c-Myc promoter to suppress c-Myc expression at the level of transcription. Then increase mitochondrial phosphorylation to promote cell movement and ultimately maintain stem cell-like characteristics in lung cancer [57].

\section{Protein interactions}

As well as functioning as transcription factors, numbers of ZFPs that can induce protein interactions have also been identified in recent years [58]. For example, the striated muscle RING zinc finger protein (SMRZ) is a novel human striated muscle ZFP which has a ring domain at its $\mathrm{N}$-terminal. In recent studies, the SMRZ was reported to interact with SMT3b, which was a ubiquitin-like protein, and their interactions are completed by the ring domain of SMRZ. This kind of interaction may contribute to the regulation of cell cycle that occurs during the process of growth in striated muscle cells [59].

\section{Post-transcriptional regulation}

Some ZFPs also have RNA binding properties, and these ZFPs are generally thought to be involved in posttranscriptional regulatory processes such as mRNA maturation splicing and degradation [60, 61]. Recently, the zinc finger protein Regnase-1, which had been revealed to regulate self-renewal of HSPCs (Hematopoietic Stem and Progenitor Cells) through modulating mRNA stability. More specifically, Regnase- 1 could degrade the mRNAs of Gata 2 and Tal1 by targeting the 3'UTR region of their mRNAs, and caused a decrease in the expression of GATA2 and Tal1, which could ultimately lead to a slowdown in the self-renewal of HSPCs and affected the homeostasis of HSPCs [62].

\section{Effects of ZFPs via different mechanisms Lipid metabolism}

An increasing number of studies have shown that metabolic manipulate and signaling pathways are closely linked, not only in normal cells but also in cancer cells [63]. Recently, Li et al. suggested that YY1 prevented proliferator-activated receptor gamma coactivator- $1 \beta$ (PGC-1 $\beta$ ) expression by directly binding to its promoter, thereby inhibiting the oxidation of fatty acid $\beta$, which led to the accumulation of lipid in HCC cells and induced the carcinogenic potentiality of $\mathrm{HCC}$ cells. It was worth mentioning that the reduction of the PGC- $1 \beta$ expression level by YY1 was independent of HIF-1 $\alpha$ (hypoxia-inducible factor-1 $\alpha$ ) expression. This provided us with new insights into the conditions under which HIF$1 \alpha$ works [64-66]. Liu et al. revealed that ZBTB20, a regulator of lipid homeostasis, promoted hepatic de novo lipogenesis (DNL) by directly binding to and enhancing the activity of the ChREBP- $\alpha$ promoter and indirectly activating ChREBP- $\beta$, which provided new insights into the transcriptional regulatory network of DNL and had the potential to be a target for the treatment of fatty liver disease (FLD) [67].

\section{Cell differentiation}

ZFPs like Snails (Snai1, Snai2/Slug, Snai3/Smuc) and the E-box binding proteins ZEBs (ZEB1, ZEB2) can also affect the process of cell differentiation directly or indirectly [68]. Goossens et al. demonstrated that ZEB2 had high mRNA levels in hematopoietic stem cells and hematopoietic progenitor cells (HPCs). Sophisticated 
cellular analysis showed that ZEB2 was imperative for normal HSC/HPC differentiation, and ZEB2 deficient HSCs/HPCs were not properly implanted in fetal liver or bone marrow, and exhibited boosted adhesion associated with upregulated expression of beta1 integrator and CXCR4 [69-74]. Tang et al. expounded that Snail and Slug could cooperatively control skeletal stem/stromal cell (SSC) self-renewal in knockout mouse models. Mechanistically, Snail/Slug were reported to regulate SSC function by forming a complex with transcriptional co-activators YAP and TAZ, thereby inhibiting the Hippo pathway-dependent YAP/TAZ signaling cascade regulation. The regulatory network within the above mechanism provides new thought on cell differentiation in normal hepatocytes and HCC cells [75]. In addition, snail can also be involved in regulating cell stemness in glioma stem cells (GSCs). A recent study revealed that snail could inhibit TGF $\beta 1$ transcription and reduce its activity through a positive feedback loop resulting from its interaction with SMAD. This process contributes to regulation of the opposite BMP and TGF $\beta$ pathway activity, thereby inhibiting GSC stemness ultimately [76].

\section{Immune response}

Few ZFPs have recently been reported in immunerelated processes such as immune response, immune homeostasis, and cytokine production in emerged new studies [77, 78].

Gfil, which function as a transcriptional repressor, is a zinc finger protein that participates in diverse development contexts. Jin et al. demonstrated that Gfil (growth factor independent 1 transcriptional repressor) played a limiting role in the inflammatory response induced by endotoxin in mouse lung, and its regulatory function in alveolar macrophages as downstream of LPS (Lipopolysaccharide) receptor (TLR4) and upstream of TNF further elucidated the mechanism of Gfi1's role in the endotoxin response [79]. By the way, the toll-like receptor (TLR) family plays a directive role in inflammatory response, antiviral, and activation of transcription factors [80]. Moreover, ZFYVE1 (zinc finger FYVE-type containing 1) can bind to poly(I:C) and TLR3 (Toll-like receptor 3) through the FYVE structural domain and enhance its association with TLR3 in response to poly(I:C) stimulation. Subsequent overexpression of ZFYVE1 can also significantly promote the binding of TLR3 to its ligand poly(I:C). Although the absence of ZFYVE1 can inhibit TLR3-mediated innate immune and inflammatory responses, it cannot inhibit TLR4-mediated the same reactions as TLR3 [81]. The above roles of these ZFPs in innate immunity and the associated inflammatory response provide deep thinking for subsequent studies.

$\mathrm{CCCH}$ zinc finger proteins consist of several $\mathrm{CCCH}$ zinc finger domains, which are composed of one histidine and three cysteines. A small number of $\mathrm{CCCH}$ zinc finger proteins have been reported to play important roles in immune responses [82, 83]. For instance, TTP (aka ZFP36), roquin 1 and MCPIP1, can form a regulatory network that maintains immune homeostasis [84-86]. The regulatory network composed of these three ZFPs accelerates the regression of inflammation, manage the sizes and rhythms of the adaptive immune response, targets mRNA to regulate its half-life and regulates signal pathways [87, 88]. However, based on the characteristics of this type of ZFP that can shuttle between different cell compartments, there is still a lot to be studied, especially in cell metabolism and cellular immunity [89].

\section{Zinc finger proteins in HCC}

In the past decades, the role of ZFPs has been reported in various of cancers including nasopharynx, esophagus, lung, gastric, colorectal, breast, thyroid, prostate, ovarian cancer [57, 90-97]. However, the number of studies in $\mathrm{HCC}$ is much less than other cancer types, and there are very few systematic reviews about HCC [98-101]. To provide a better understanding of ZFPs in HCC and explore the potential therapeutic targets. Here, we firstly summarize the functions of ZFPs in HCC and the specific mechanisms (Tables 1 and 2), and some specific examples are shown in the form of figure (Fig. 2).

\section{Cell cycle}

The cell cycle regulation cannot be separated from cyclins, CDKs (Cyclin-dependent kinases) and CKIs (Cyclin-dependent kinase inhibitors) [114]. CDC6 (cell division cycle 6) is a protein essential for the initiation of DNA replication [102]. The overexpression of ZNF143 facilitated HCC cell cycle progression via activating CDC6. Concretely, ZNF143 was reported to directly activate transcription of histone demethylase mineral dustinduced gene (MDIG) and decreased the enrichment of H3K9me3 in the CDC6 promoter region [115]. In addition, Cyclin D1 could form a complex with CDK4 or CDK6, whose activity was required for cell cycle progression [116]. He et al. demonstrated that knockdown of ZNF384 could result in sluggish of the G1/S phase transition in HCC. Mechanistically, ZNF384 was found to upregulate Cyclin D1 by binding to its promoter region, then accelerated $\mathrm{G} 1 / \mathrm{S}$ phase transition and promotes proliferation of HCC [110].

\section{Apoptosis}

The process of apoptosis is induced by two distinct pathways: the intracellular pathway or the extracellular pathway [117]. In the extracellular pathway, apoptosis begins with binding a family of death receptors to an appropriate ligand on the membrane, then the death- 
Table 1 Oncogenic role of ZFPs in HCC

\begin{tabular}{llllll}
\hline ZFPs & Aliases & Role & Target genes & Mechanism in HCC & Ref \\
\hline ZNF384 & NMP4、CAGH1 & Oncogene & Cyclin D1 & Promotes proliferation & [102] \\
ZNF263 & ZSCAN44、FPM315 & Oncogene & Beclin1、LC3 & Promotes proliferation, chemotherapy resistance and inhibits apoptosis & [103] \\
ZNF703 & NLZ1、ZPO1 & Oncogene & CLDN4 & Induces EMT progress \\
ZNF687 & PDB6 & Oncogene & BMI1、OCT4、Nanog & Enhances invasion and chemoresistance & [104] \\
ZNF143 & SBF、STAF & Oncogene & MDIG & Promotes proliferation and tumor growth & [7] \\
ZNF191 & ZNF24、ZSCAN3 & Oncogene & CTNNB1 & Activates Wnt signaling pathway & [101] \\
ZNF503 & NIZ2、NOLZ1 & Oncogene & GATA3 & Promotes migration, invasion and EMT progress \\
ZFX & ZNF926 & Oncogene & Nanog、SOX-2 & Enhances proliferation, drug resistance, and the ability of self-renewal & [107] \\
Gli1 & PPD1、PAPA8 & Oncogene & MMP-2、MMP-9 & Promotes migration and invasion & [8] \\
& & & Caveolin-1 & Induces EMT and promotes the motility and invasion
\end{tabular}

inducing signaling complex (DISC) is recruited and activated, which consists of FADD (Fas-Associated protein with Death Domain), the death-executing protease enzyme caspase-8 and FLIP [118]. Liang et al. revealed that overexpression of ZNF307 upregulated the protein level of caspase-3 and Bax (BCL2 associated X), while decreased the protein level of Bcl-2 (BCL2 apoptosis regulator). It was the first time that ZNF307 was reported to function as tumor suppressor in HCC by inducing apoptosis by targeting these genes [103]. It was worth mentioning that Bax and Bcl-2 is also regulated by other ZFP in HCC. In a previous study, GLI1 was aberrantly overexpressed in HCC [119]. PCAF modulated the GLI1/ Bcl-2/BAX axis to induce apoptosis in HCC. Gai et al. suggested that the cytoplasmic GLI1 protein was acetylated directly at lysine 518 by PCAF (P300/CBP-associated factor), while the nuclear translocation and promoter occupancy of GLI1 were prevented. Subsequently, the expression of Bcl-2 was decreased, and BAX was increased [120]. Additionally, ZNF263 could promote resistance to apoptosis in HCC indirectly by activating ER stress-dependent autophagy, and the specific mechanism has not been further investigated [121].

\section{Stemness maintenance}

Cancer stem cells (CSCs) are responsible for selfrenewal, maintenance, and the growth of tumors [122]. The ability of CSCs to evade cell death and metastasis is significant for tumorigenesis [107, 123]. Zinc finger protein X-linked (ZFX), which was highly conserved in vertebrates. According to previous studies, ZFX was concerned with the initiation or progression in various of human cancers $[124,125]$. Recently, Lai et al. demonstrated that overexpression of ZFX leaded to the upregulation of Nanog and SOX-2, which could play a vital role in the development of embryonic stem cells (ESCs) [126]. Mechanistically, ZFX could bind to the promoter of Nanog and SOX-2 directly and activate their expression, then contributed to the maintenance of stem-like characteristics of HCC cells [127]. Similarly, ZFX could also upregulate the expression of epithelial cell adhesion molecule (EpCAM) in HCC. Specifically, knocking-down

Table 2 Tumor-suppressive roles of ZFPs in HCC

\begin{tabular}{|c|c|c|c|c|c|}
\hline ZFPs & Aliases & Role & Target genes & Mechanism in HCC & Ref \\
\hline \multirow[t]{3}{*}{$\mathrm{A} 20$} & TNFA1P2 & TSG & Twist1 & Inhibits proliferation and migration & [98] \\
\hline & & & FAK、RAC1 & Inhibits the motility and metastasis & [11] \\
\hline & & & PFKL & Inhibits proliferation, migration and glycolysis & [108] \\
\hline GATA4 & TOF、ASD2 & TSG & NF-KB1, NF-KB2, RELA & Induces the MET transition & [109] \\
\hline ZNF307 & ZKSCAN4 & TSG & Caspase-3、BAX、BCL-2 & Inhibits proliferation & [110] \\
\hline ZNF191 & ZNF24、ZSCAN3 & TSG & DLG1 & Inhibits metastasis of HCC & [111] \\
\hline ZFP91 & PZF、ZNF757 & TSG & HNRNPA1 & Inhibits glucose metabolic reprogramming, proliferation and metastasis & [112] \\
\hline ZNF382 & KS1 & TSG & Fos, Jun, DVL2、FZD1 & Activates the p53 signaling pathway & [12] \\
\hline ZNF774 & & TSG & $\mathrm{NOTCH} 2$ & Inhibits growth and metastasis of HCC & [13] \\
\hline Miz1 & ZBTB17、ZNF60 & TSG & MTDH & Inhibits inflammation & [113] \\
\hline ZNF521 & EHZF、Evi3 & TSG & Runx2 & Inhibits growth & [14] \\
\hline
\end{tabular}




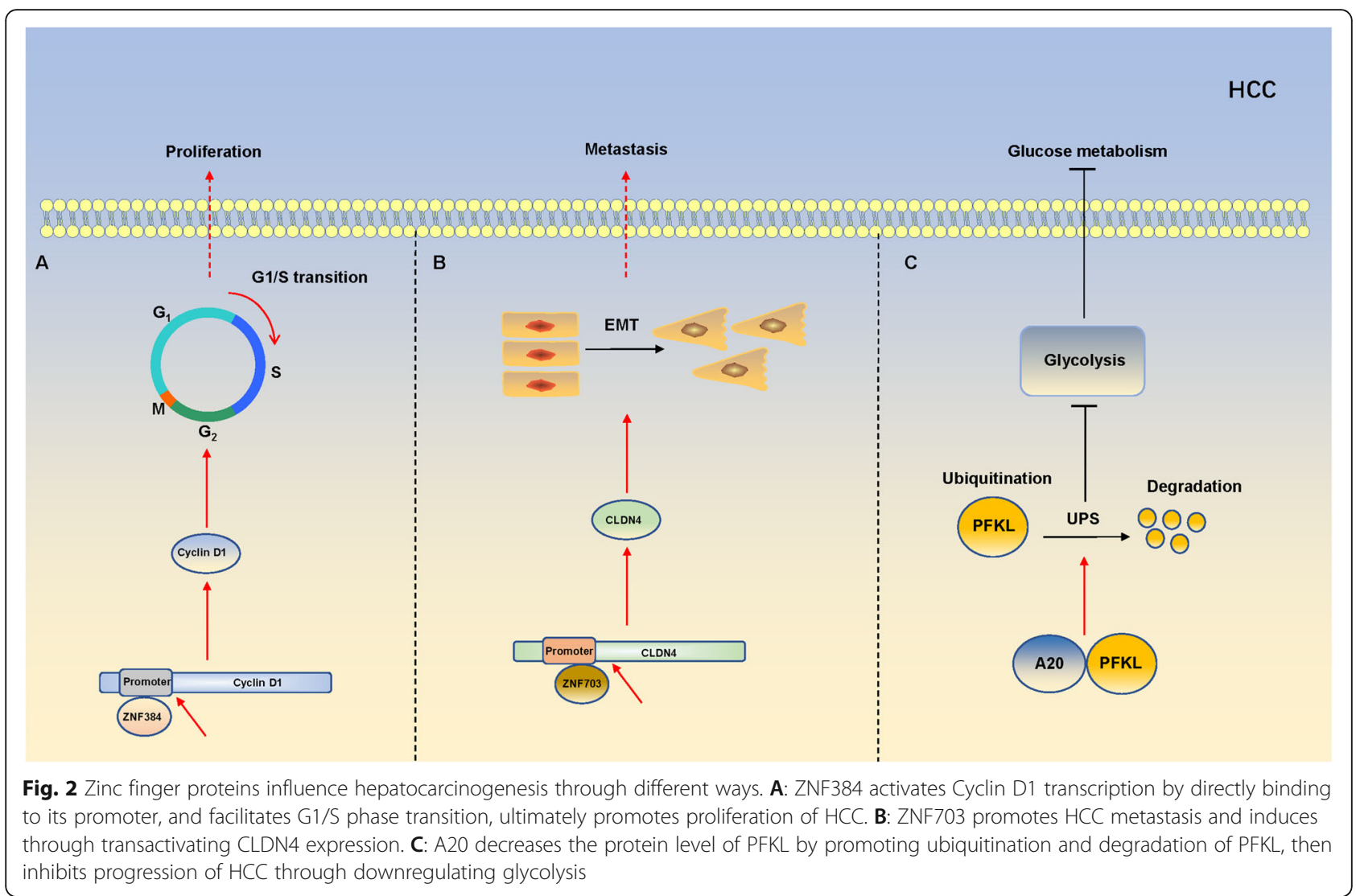

of ZFX could inhibit CSCs-associated gene expression, self-renewal capacity, metastatic potential and tumorigenicity. Depletion of ZFX was demonstrated to reduce the transactivation and nuclear translocation of $\beta$ catenin and maintained the stemness of liver CSCs by activating $\beta$-catenin. The expression level of ZFX and EpCAM could be a significant prognostic factor of patients in HCC [128].

\section{EMT and metastasis}

The epithelial to mesenchymal transition (EMT) plays a meaningful role in the early steps of metastasis of tumor [104]. In a previous study, TGF- $\beta$ had been identified as one of the most potential inducer of EMT, which could play a dual role by performing an anti-oncogenic effect at the early stages of tumor and being oncogenic at later stages [109, 129]. As one of the classic EMT activators, ZEB1 plays a significant role in HCC. Li et al. suggested that ZEB1 markedly enhanced the Wnt signaling pathway, promoted the proliferation and migration of $\mathrm{HCC}$, and this phenomenon could be abolished by miR-708 [130]. This regulatory mechanism might provide a new therapeutic target for the treatment of HCC. In addition, Snail, another classic transcription factor, is also involved in the induction of EMT. For example, Jiao et al. demonstrated that Snail and E-cadherin are negatively correlated with mRNA and protein levels in HCC cells, and the high expression level of Snail in HCC often indicates a poor prognosis [131]. Recently, Wang et al. revealed that ZNF703 overexpression could promote HCC metastasis and sorafenib resistance by regulating EMT via upregulating CLDN4. Precisely, ZNF703 activated CLDN4 by binding directly to promoter of CLDN4. Moreover, the Kaplan-Meier analysis showed that ZNF703 could be considered as an indicator for predicting the prognosis of patients with HCC [106]. GATA4 was shown as a ZFP that was identified as a regulator of cardiac development and adult cardiac hypertrophy [132]. Overexpression of GATA4 could lead to the upregulation of E-cadherin and the downregulation of $\mathrm{N}$ cadherin and vimentin, which were vital markers in the EMT process. This phenomenon could result in the mesenchymal-to-epithelial transition of HCC cells, but the specific mechanism was still unknown [133]. ZNF503 was reported to function as a transcriptional repressor in breast cancer and increase mammary epithelial cell proliferation [112, 134]. Recently, the role of ZNF503 in the development of HCC and tumor initiation was uncovered. Yin et al. suggested that mRNA level and protein level of ZNF503 were upregulated in HCC tissues and cell lines. Additionally, ZNF503 could promotes invasion, migration, and EMT processes in 
HCC. Mechanistically, ZNF503 was demonstrated to be recruited to promoter of GATA4, then represses its expression, which played a reverse role of ZNF503 [135].

\section{Metabolism reprogramming and glucose metabolism}

Cellular metabolism functions as a flexible network not only in normal tissues but also in the development of malignancies [136]. Metabolic reprogramming is the process that tumor cells reprogram the acquisition and metabolism of nutrients to meet their needs for energy, protein synthesis, and maintenance of redox homeostasis [137]. In the past decades, ZFP91 had been reported to be associated with inflammatory response but rarely studied in the metabolism reprogramming [138]. Recently, Chen et al. demonstrated that ZFP91 could inhibit hnRNP A1-dependent PKM splicing and ultimately suppress glucose metabolism reprogramming, cell proliferation and metastasis of HCC. Specifically, overexpression of ZFP91 could promote the Lys48-linked ubiquitination of hnRNP A1 at lysine 8 and proteasomal degradation, which could block the process of hnRNP A1-dependent PKM splicing, and result in the downregulation of PKM2 (Pyruvate kinase M2) and the upregulation of PKM1 (Pyruvate kinase M1) [139]. The formation of PKM2 is critical in the Warburg effect in cancer cells [108]. The Warburg effect causes an increase in glucose uptake and lactate production, which provides a selective advantage for tumor progression [140]. From the perspective of treatment, blocking up the ZFP91hnRNP A1 pathways may be an effective method in the future.

A20, also known as tumor necrosis factor $\alpha$-induced protein 3 (TNFAIP3), is an E3 ubiquitin ligase containing ring finger domains and is also a hotpot in immunoregulation [113, 141, 142]. Recently, A20 was found to correlate with glucose metabolism. Feng et al. revealed that A20 could interact with PFKL (phosphofructokinase, liver type) and promote its ubiquitination and degradation, thus inhibiting glycolysis in HCC cell lines and ultimately inhibiting proliferation, migration, and glycolysis of HCC [143]. PFK (phosphofructokinase) was found as the most important rate-limiting enzyme in glycolysis, and PFKL was one of its isoforms in the human liver [144, 145]. This study filled the gap in the glycolytic pathway and provided possible therapeutic targets for HCC treatment.

\section{Regulation of inflammation}

Liver is the main organ where immune response and immune tolerance occur, and many immune reactions in normal hepatocytes and HCC cells may impact on the immune function of the liver [146]. Recently, several researches showed that ZFPs could influence important process of immune responses. Fortunately, Zhang et al. suggested that the ZFP Miz1 could suppress liver tumorigenesis by restraining hepatocyte-driven macrophage activation and inflammation [105, 147]. On the one hand, the cytosolic Miz1 could interfere with the interaction between MTDH and RelA through competitive binding, thereby limiting DEN/ccl4-induced activation of NF-kB in hepatocytes in HCC. Additionally, Miz1 could inhibit MTDH phosphorylation by IKK (the IkB kinase complex), which was an activator of NF-kB after activated by varies extracellular stimuli, then inhibiting NF-kB transcriptional activity [111]. On the other hand, hepatocyte-specific Miz1 decrease produced a unique hepatocytes subset with the up-regulation level of TNF- $\alpha$, IL-1b, IL-6, and CCL4, which promoted tumor-infiltrating macrophages to a pro-inflammatory phenotype, thereby promoting an inflammatory response in HCC.

\section{ZNF191: double-edged sword in HCC}

In most conditions, ZFPs tend to play only one of the two effects, anti-oncogenic or oncogenic. However, during the past few years, some studies have shown that one ZFP may play both oncogenic and tumorsuppressive roles in HCC (Fig. 3). ZNF191, also known as ZNF24, belongs to the scan domain family's transcription factors containing Krüppel-like zinc finger. It includes four zinc finger motifs that can encode potential DNA binding regions [148]. As a transcription factor that recognizes the TCAT motif explicitly, it plays an essential role in mammalian development, especially during the embryonic period. Within other areas of physiological function, it has been reported to promote the migration of endothelial cells and vascular smooth muscle cells and even promote DNA replication [148150]. In HCC, ZNF191 was initially reported to enhance the transcriptional activity of $\beta$-catenin by binding to nucleotides located at $-1254 /-1224$ on its promoter region, thereby upregulated the expression of its downstream target gene cyclinD1 and ultimately promoting the proliferation of HCC cells [151]. A few years later, the same team's research about ZNF191 in HCC emerged, and this time it was playing an adverse role. Wu et al. revealed that ZNF191 activated DLG1 expression by directly binding to the DLG1 promoter through its typical TCAT repeat sequence, subsequently inhibiting the migration and YAP activation of HCC cells and ultimately the metastasis of HCC [152]. Recently, another study revealed that ZNF191 could activate the WNT signaling pathway through transcriptional upregulation of Wnt8B, which ultimately promoted the proliferation of HCC. Like $\beta$-catenin, the promoter region of Wnt8B was bound by ZNF191, which in turn enhanced Wnt8B transcriptional activity, thereby activating the Wnt signaling pathway [153]. It was worth noting that the two mechanisms could co-exist in HCC, which 


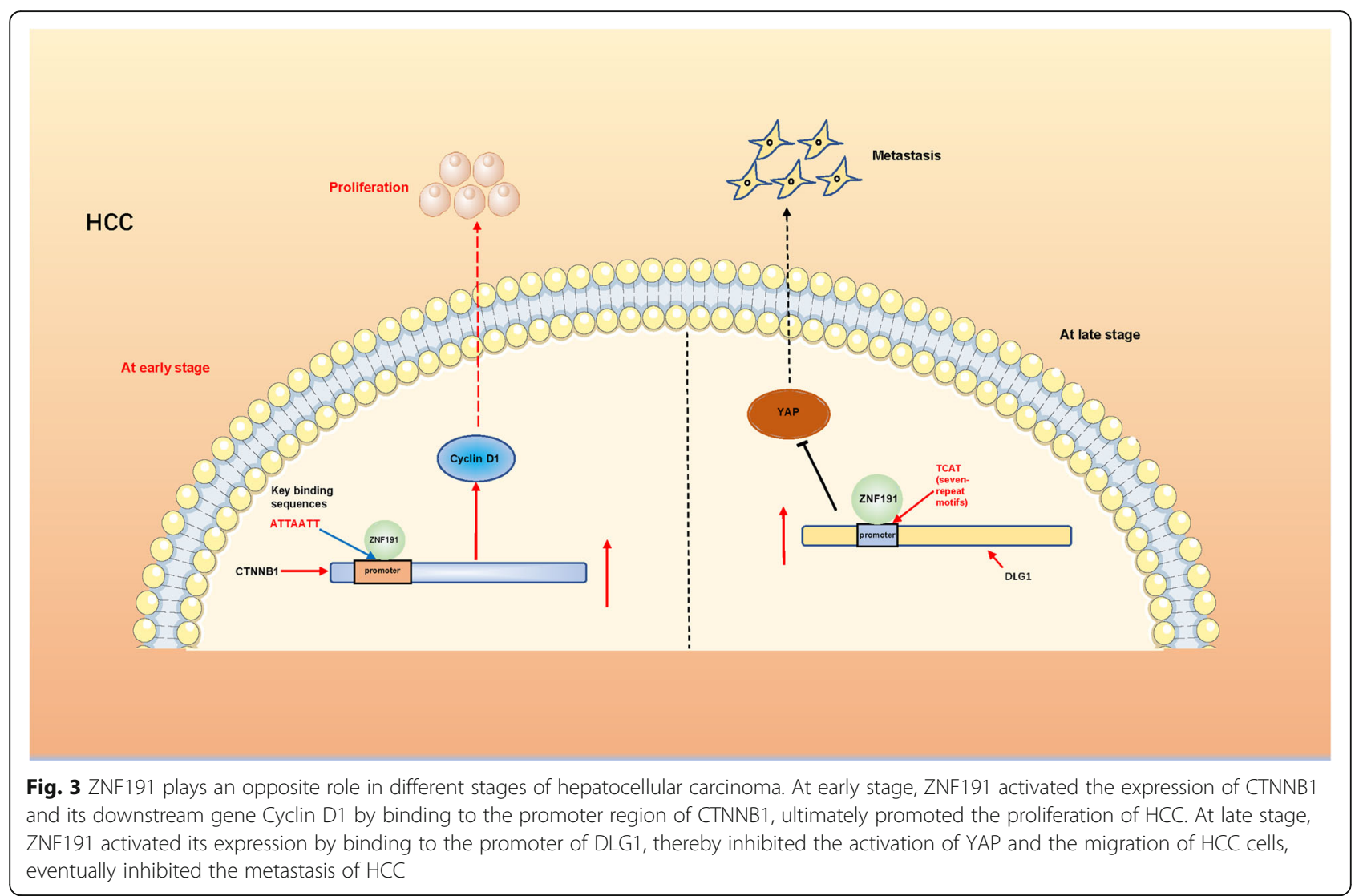

exerted both promotion and inhibition functions. Consequently, the expression level of ZNF191 and associated disease background must be clarified before targeting therapy for ZNF191-associated HCC, and the coexistence of these two mechanisms in the context of ZNF191 also deserves further investigation. We believe that ZNF191 has the potential to be a prognostic factor for HCC and a key therapeutic target as research progresses.

\section{Conclusion and perspectives}

As one of the largest transcription factor families in the human genome, ZFPs play diverse roles in cell biological functions, such as cell differentiation, apoptosis, transcriptional regulation, cell metabolism, immune response. In the past decades, there have been more reports about the role of ZFP in cancer, especially in HCC. HCC is still one of the cancers with the highest mortality rate in the world with many unsolved problems for early diagnosis and postoperative treatment. In this review, we described the role and related mechanisms of ZFPs in the development of HCC.

Above all, zinc finger motifs have different types, including Cys2His2 (C2H2) like, Gag knuckle, Treble clef, Zinc ribbon, Zn2/Cys6, TAZ2 domain like, Zinc binding loops and Metallothionein. The $\mathrm{C} 2 \mathrm{H} 2$ zinc finger motif is the largest of all zinc finger motifs. In the $\mathrm{C} 2 \mathrm{H} 2$ motif ZFP, in addition to the zinc finger structure, also contains other common domains, such as the KRAB domain, the BTB domain, SCAN domain and SET domain. These domains could bind to DNA, RNA or proteins to function. Secondly, ZFPs were also reported in regulating posttranscriptional modification and protein-protein interaction. Finally, ZFPs affect the development of HCC in different processes, such as cell cycle, apoptosis and even metabolism. Among them, ZNF191 shows a distinct effect in the early and late stages of HCC. Some ZFPs have also been reported as prognostic factors in HCC. For example, the high expression of ZBTB20 and ZNF689 in HCC patients was strongly associated with poor clinical prognosis as well as high recurrence rates [154, 155]. In a latest study, Sun et al. revealed that zinc finger protein 2 gene (ZIC2) was able to predict the prognosis of HCC, and ZIC2 was positively correlated with immune infiltration cells in HCC patients [156]. Therefore, due to the different roles that ZFPs play in HCC, it is possible to invent inhibitors for a specific ZFP or to interfere with the expression of its target gene, and these approaches may provide new thinking about ZFPs in HCC and even in other cancers.

In a word, ZFPs play an important role in tumorigenesis of HCC, and more mechanisms need to be further studied. The targeted drugs of ZFPs in HCC need to be further explored. 


\section{Abbreviations}

ZNF: zinc finger; HCC: hepatocellular carcinoma; HBV: hepatitis B virus; HCV: hepatitis C virus; ZFP: zinc finger protein; TF: transcription factor; C2H2: cys2his2; BTB: Broad-complex, Tramtrack, and Bric-a-brac; KRAB: Krüppel-associated box; SCAN: SRE-ZBP, CTfin51, AW-1 and Number 18 CDNA; POZ: poxvirus and zinc finger; ZSCAN: zinc finger and scan; KZFPS: Krüppel-associated box domain-containing zinc finger proteins; TEs: transposable elements; ES: embryonic stem; Trx: trithorax; SAM: Sadenosyl-L-methionine; ZEB1: zinc finger E-box binding homeobox 1; HDGF: hepatoma-derived growth factor; EC: endometrial carcinoma; SMRZ: striated muscle ring zinc finger protein; HSPCs: hematopoietic stem and progenitor cells; PGC-1 $\beta$ : proliferator-activated receptor gamma coactivator-1 $\beta$; HIF-1a: hypoxia-inducible factor-1a; DNL: de novo lipogenesis; FLD: fatty liver disease; HPCs: hematopoietic progenitor cells; SSC: skeletal stem/stromal cell; GSCs: glioma stem cells; Gfi1: growth factor independent 1 transcriptional repressor; LPS: lipopolysaccharide; TLR: toll-like receptor; ZFYVE1: zinc finger FYVE-type containing 1; TLR3: toll-like receptor 3; IL17R: IL-17 receptor; ER: endoplasmic reticulum; CDKs: cyclin-dependent kinases; CKls: cyclin-dependent kinase inhibitors; CDC6: cell division cycle 6; MDIG: mineral dust-induced gene; DISC: death-inducing signaling complex; FADD: fas-associated protein with death domain; Bax: bcl2 associated $\mathrm{x} ; \mathrm{BCl}$ 2: bcl2 apoptosis regulator; PCAF: p300/cbp-associated factor; CSCs: cancer stem cells; ZFX: zinc finger protein $x$-linked; ESCs: embryonic stem cells; EpCAM: epithelial cell adhesion molecule; EMT: epithelial to mesenchymal transition; PKM2: pyruvate kinase m2; PKM1: pyruvate kinase m1; TNFA IP3: tumor necrosis factora-induced protein 3; PFKL: phosphofructokinase, liver type; PFK: phosphofructokinase; IKK: the IkB kinase complex

\section{Acknowledgments}

Not applicable.

\section{Authors' contributions}

All authors wrote, revised and approved the final manuscript.

\section{Funding}

None.

\section{Availability of data and materials}

Not applicable.

\section{Declarations}

Ethics approval and consent to participate

Not applicable.

\section{Consent for publication}

Not applicable.

\section{Competing interests}

The authors have declared that no competing interest exists.

\section{Author details}

${ }^{1}$ Hepatic Surgery Center, Tongji Hospital, Tongji Medical College, Huazhong University of Science and Technology, 1095 Jiefang Avenue, Wuhan 430030 China. ${ }^{2}$ Hubei Key Laboratory of Hepato-Pancreato-Biliary Diseases, Wuhan 430030, China.

Received: 4 October 2021 Accepted: 23 November 2021

Published online: 09 January 2022

\section{References}

1. Kim S, Shendure J. Mechanisms of interplay between transcription factors and the 3D genome. Mol Cell. 2019;76(2):306-19. https://doi.org/10.1016/j. molcel.2019.08.010.

2. Chen A, Koehler AN. Transcription factor inhibition: lessons learned and emerging targets. Trends Mol Med. 2020;26:508-18.

3. Krishna SS, Majumdar I, Grishin NV. Structural classification of zinc fingers: survey and summary. Nucleic Acids Res. 2003;31:532-50.

4. Jen J, Wang YC. Zinc finger proteins in cancer progression. J Biomed Sci. 2016;23:53.
5. Gong D, Feng PC, Ke XF, Kuang HL, Pan LL, Ye Q, et al. Silencing long noncoding RNA LINC01224 inhibits hepatocellular carcinoma progression via MicroRNA-330-5p-induced inhibition of CHEK1. Mol Ther Nucleic Acids. 2020;19:482-97.

6. McGlynn KA, Petrick JL, El-Serag HB. Epidemiology of hepatocellular carcinoma. Hepatology. 2021;73(Suppl 1):4-13.

7. Zhang T, Huang Y, Liu W, Meng W, Zhao H, Yang Q, et al. Overexpression of zinc finger protein 687 enhances tumorigenic capability and promotes recurrence of hepatocellular carcinoma. Oncogenesis. 2017;6(7):e363. https://doi.org/10.1038/oncsis.2017.63.

8. Chen J, Li H, Huang J, Zhang L, Chen X, Wang Q, et al. Down-regulation of Gli-1 inhibits hepatocellular carcinoma cell migration and invasion. Mol Cell Biochem. 2014:393:283-91.

9. Gai X, Lu Z, Tu K, Liang Z, Zheng X, Müller R. Caveolin-1 is up-regulated by GLI1 and contributes to GLI1-driven EMT in hepatocellular carcinoma. PLoS One. 2014;9:e84551

10. Li J, He Y, Cao Y, Yu Y, Chen X, Gao X, et al. Upregulation of twist is involved in Gli1 induced migration and invasion of hepatocarcinoma cells. Biol Chem. 2018;399:911-9.

11. Yi PS, Shu Y, Bi WX, Zheng XB, Feng WJ, He LY, et al. Emerging role of zinc finger protein A20 as a suppressor of hepatocellular carcinoma. J Cell Physiol. 2019;234:21479-84

12. Dang S, Zhou J, Chen Y, Chen P, Ji M, Shi B, et al. Dynamic expression of ZNF382 and its tumor-suppressor role in hepatitis B virus-related hepatocellular carcinogenesis. Oncogene. 2019;38(24):4804-19. https://doi. org/10.1038/s41388-019-0759-9.

13. Guan C, He L, Chang Z, Gu X, Liang J, Liu R. ZNF774 is a potent suppressor of hepatocarcinogenesis through dampening the NOTCH2 signaling. Oncogene. 2020;39:1665-80.

14. Yang N, Wang L, Chen T, Liu R, Liu Z, Zhang L. ZNF521 which is downregulated by miR-802 suppresses malignant progression of hepatocellular carcinoma through regulating Runx2 expression. J Cancer. 2020;11:5831-9.

15. Han M, Liao Z, Liu F, Chen X, Zhang B. Modulation of the TGF-beta signaling pathway by long noncoding RNA in hepatocellular carcinoma. Biomark Res. 2020:8:70.

16. Perez-Torrado R, Yamada D, Defossez PA. Born to bind: the BTB proteinprotein interaction domain. Bioessays. 2006:28(12):1194-202. https://doi. org/10.1002/bies.20500.

17. Bardwell VJ, Treisman R. The POZ domain: a conserved protein-protein interaction motif. Genes Dev. 1994;8:1664-77.

18. Stogios PJ, Downs GS, Jauhal JJ, Nandra SK, Prive GG. Sequence and structural analysis of BTB domain proteins. Genome Biol. 2005;6:R82.

19. Ahmad KF, Melnick A, Lax S, Bouchard D, Liu J, Kiang CL, et al. Mechanism of SMRT corepressor recruitment by the BCL6 BTB domain. Mol Cell. 2003; 12:1551-64.

20. Kang MI, Kobayashi A, Wakabayashi N, Kim SG, Yamamoto M. Scaffolding of Keap1 to the actin cytoskeleton controls the function of Nrf2 as key regulator of cytoprotective phase 2 genes. Proc Natl Acad Sci U S A. 2004 101(7):2046-51. https://doi.org/10.1073/pnas.0308347100.

21. Kreusch A, Pfaffinger PJ, Stevens CF, Choe S. Crystal structure of the tetramerization domain of the shaker potassium channel. Nature. 1998; 392(6679):945-8. https://doi.org/10.1038/31978.

22. Furukawa M, He YJ, Borchers C, Xiong Y. Targeting of protein ubiquitination by BTB-Cullin 3-Roc1 ubiquitin ligases. Nat Cell Biol. 2003:5:1001-7.

23. Geyer R, Wee $S$, Anderson S, Yates J, Wolf DA. BTB/POZ domain proteins are putative substrate adaptors for cullin 3 ubiquitin ligases. Mol Cell. 2003;12(3): 783-90. https://doi.org/10.1016/S1097-2765(03)00341-1.

24. Filion GJ, Zhenilo S, Salozhin S, Yamada D, Prokhortchouk E, Defossez PA. A family of human zinc finger proteins that bind methylated DNA and repress transcription. Mol Cell Biol. 2006;26(1):169-81. https://doi.org/10.1128/MCB.2 6.1.169-181.2006.

25. Schumacher C, Wang H, Honer C, Ding W, Koehn J, Lawrence Q, et al. The SCAN domain mediates selective oligomerization. J Biol Chem. 2000;275(22): 17173-9. https://doi.org/10.1074/jbc.M000119200.

26. Ahmad KF, Engel CK, Prive GG. Crystal structure of the BTB domain from PLZF. Proc Natl Acad Sci U S A. 1998;95:12123-8.

27. Li X, Peng H, Schultz DC, Lopez-Guisa JM, Rauscher FR, Marmorstein R Structure-function studies of the BTB/POZ transcriptional repression domain from the promyelocytic leukemia zinc finger oncoprotein. Cancer Res. 1999; 59:5275-82. 
28. Huang $M$, Chen $Y$, Han D, Lei Z, Chu X. Role of the zinc finger and SCAN domain-containing transcription factors in cancer. Am J Cancer Res. 2019; 9(5):816-36

29. Pengue G, Calabro V, Bartoli PC, Pagliuca A, Lania L. Repression of transcriptional activity at a distance by the evolutionarily conserved KRAB domain present in a subfamily of zinc finger proteins. Nucleic Acids Res. 1994;22:2908-14.

30. Sander TL, Haas AL, Peterson MJ, Morris JF. Identification of a novel SCAN box-related protein that interacts with MZF1B. The leucine-rich SCAN box mediates hetero- and homoprotein associations. J Biol Chem. 2000;275(17): 12857-67. https://doi.org/10.1074/jbc.275.17.12857.

31. Williams AJ, Blacklow SC, Collins T. The zinc finger-associated SCAN box is a conserved oligomerization domain. Mol Cell Biol. 1999;19(12):8526-35. https://doi.org/10.1128/MCB.19.12.8526.

32. Eguchi T, Prince T, Wegiel B, Calderwood SK. Role and regulation of myeloid zinc finger protein 1 in Cancer. J Cell Biochem. 2015;116:2146-54.

33. Bonchuk A, Boyko K, Fedotova A, Nikolaeva A, Lushchekina S, Khrustaleva A, et al. Structural basis of diversity and homodimerization specificity of zincfinger-associated domains in Drosophila. Nucleic Acids Res. 2021;49(4):237589. https://doi.org/10.1093/nar/gkab061.

34. Imbeault M, Helleboid PY, Trono D. KRAB zinc-finger proteins contribute to the evolution of gene regulatory networks. Nature. 2017;543:550-4.

35. lyengar S, Farnham PJ. KAP1 protein: an enigmatic master regulator of the genome. J Biol Chem. 2011;286:26267-76.

36. Mannini R, Rivieccio V, D'Auria S, Tanfani F, Ausili A, Facchiano A, et al. Structure/function of KRAB repression domains: structural properties of KRAB modules inferred from hydrodynamic, circular dichroism, and FTIR spectroscopic analyses. Proteins. 2006;62(3):604-16. https://doi.org/10.1002/ prot.20792.

37. Vissing H, Meyer WK, Aagaard L, Tommerup N, Thiesen HJ. Repression of transcriptional activity by heterologous KRAB domains present in zinc finger proteins. FEBS Lett. 1995;369:153-7.

38. Iuchi S. Three classes of $\mathrm{C} 2 \mathrm{H} 2$ zinc finger proteins. Cell Mol Life Sci. 2001; 58(4):625-35. https://doi.org/10.1007/PL00000885.

39. Nakahashi $H$, Kieffer KK, Resch W, Vian L, Dose M, Stavreva D, et al. A genome-wide map of CTCF multivalency redefines the CTCF code. Cell Rep. 2013;3:1678-89.

40. Schmitges FW, Radovani E, Najafabadi HS, Barazandeh M, Campitelli LF, Yin $Y$, et al. Multiparameter functional diversity of human $\mathrm{C} 2 \mathrm{H} 2$ zinc finger proteins. Genome Res. 2016;26(12):1742-52. https://doi.org/10.1101/gr.2 09643.116

41. Najafabadi HS, Mnaimneh S, Schmitges FW, Garton M, Lam KN, Yang A, et al. $\mathrm{C} 2 \mathrm{H} 2$ zinc finger proteins greatly expand the human regulatory lexicon. Nat Biotechnol. 2015;33:555-62.

42. Honer C, Chen P, Toth MJ, Schumacher C. Identification of SCAN dimerization domains in four gene families. Biochim Biophys Acta. 2001; 1517:441-8.

43. Ecco G, Imbeault M, Trono D. KRAB zinc finger proteins. Development. 2017; 144(15):2719-29. https://doi.org/10.1242/dev.132605.

44. Del Rizzo PA, Trievel RC. Substrate and product specificities of SET domain methyltransferases. Epigenetics-Us. 2011;6(9):1059-67. https://doi.org/10.41 61/epi.6.9.16069.

45. Herz H, Garruss A, Shilatifard A. SET for life: biochemical activities and biological functions of SET domain-containing proteins. Trends Biochem Sci. 2013;38(12):621-39. https://doi.org/10.1016/j.tibs.2013.09.004.

46. Jiao Z, Wang L, Du H, Wang Y, Wang W, Liu J, et al. Genome-wide study of $\mathrm{C} 2 \mathrm{H} 2$ zinc finger gene family in Medicago truncatula. BMC Plant Biol. 2020; 20(1):401. https://doi.org/10.1186/s12870-020-02619-6.

47. McCarty AS, Kleiger G, Eisenberg D, Smale ST. Selective dimerization of a C2H2 zinc finger subfamily. Mol Cell. 2003;11(2):459-70. https://doi.org/10.1 016/S1097-2765(03)00043-1.

48. Persikov AV, Wetzel JL, Rowland EF, Oakes BL, Xu DJ, Singh M, et al. A systematic survey of the Cys2His2 zinc finger DNA-binding landscape. Nucleic Acids Res. 2015;43(3):1965-84. https://doi.org/10.1093/nar/gku1395.

49. Hashimoto $H$, Wang D, Horton JR, Zhang X, Corces VG, Cheng X. Structural basis for the versatile and methylation-dependent binding of CTCF to DNA. Mol Cell. 2017;66:711-20

50. Caramel J, Ligier M, Puisieux A. Pleiotropic roles for ZEB1 in cancer. Cancer Res. 2018;78:30-5.

51. Zhang P, Sun Y, Ma L. ZEB1: at the crossroads of epithelial-mesenchymal transition, metastasis and therapy resistance. Cell Cycle. 2015;14(4):481-7. https://doi.org/10.1080/15384101.2015.1006048.
52. Schroth GP, Cook GR, Bradbury EM, Gottesfeld JM. Transcription factor IIIA induced bending of the Xenopus somatic 55 gene promoter. Nature. 1989; 340(6233):487-8. https://doi.org/10.1038/340487a0.

53. Schleif R. DNA binding by proteins. Science. 1988;241:1182-7.

54. Moroy T, Khandanpour C. Role of GFI1 in epigenetic regulation of MDS and AML pathogenesis: mechanisms and therapeutic implications. Front Oncol. 2019;9:824.

55. Wolf G, Greenberg D, Macfarlan TS. Spotting the enemy within: targeted silencing of foreign DNA in mammalian genomes by the Kruppel-associated box zinc finger protein family. Mob DNA. 2015;6:17.

56. Xiao YY, Lin L, Li YH, Jiang HP, Zhu LT, Deng YR, et al. ZEB1 promotes invasion and metastasis of endometrial cancer by interacting with HDGF and inducing its transcription. Am J Cancer Res. 2019;9:2314-30.

57. Jen J, Liu CY, Chen YT, Wu LT, Shieh YC, Lai WW, et al. Oncogenic zinc finger protein ZNF322A promotes stem cell-like properties in lung cancer through transcriptional suppression of c-Myc expression. Cell Death Differ. 2019:26(7):1283-98. https://doi.org/10.1038/s41418-018-0204-6.

58. Orth B, Sander B, Moglich A, Diederichs K, Eilers M, Lorenz S. Identification of an atypical interaction site in the BTB domain of the MYC-interacting zinc-finger protein 1. Structure. 2021;29(11):1230-40.e5. https://doi.org/10.1 016/j.str.2021.06.005

59. Dai KS, Liew CC. A novel human striated muscle RING zinc finger protein, SMRZ, interacts with SMT3b via its RING domain. J Biol Chem. 2001;276(26): 23992-9. https://doi.org/10.1074/jbc.M011208200.

60. Yi D, Dempersmier JM, Nguyen HP, Viscarra JA, Dinh J, Tabuchi C, et al. Zc3h10 acts as a transcription factor and is phosphorylated to activate the thermogenic program. Cell Rep. 2019;29:2621-33.

61. Makita S, Takatori H, Nakajima H. Post-transcriptional regulation of immune responses and inflammatory diseases by RNA-binding ZFP36 family proteins. Front Immunol. 2021;12:711633. https://doi.org/10.3389/fimmu.2 021.711633

62. Kidoya H, Muramatsu F, Shimamura T, Jia W, Satoh T, Hayashi Y, et al. Regnase-1-mediated post-transcriptional regulation is essential for hematopoietic stem and progenitor cell homeostasis. Nat Commun. 2019; 10(1):1072. https://doi.org/10.1038/s41467-019-09028-w.

63. Vander HM, Cantley LC, Thompson CB. Understanding the Warburg effect: the metabolic requirements of cell proliferation. Science. 2009;324:1029-33.

64. Li Y, Kasim V, Yan X, Li L, Meliala I, Huang C, et al. Yin Yang 1 facilitates hepatocellular carcinoma cell lipid metabolism and tumor progression by inhibiting PGC-1 beta-induced fatty acid oxidation. Theranostics. 2019;9(25): 7599-615. https://doi.org/10.7150/thno.34931.

65. Huang LT, Li X, Zhang L, Sun L, He X, et al. HIF-1-mediated suppression of acyl-CoA dehydrogenases and fatty acid oxidation is critical for cancer progression. Cell Rep. 2014:8:1930-42.

66. Wu S, Kasim V, Kano MR, Tanaka S, Ohba S, Miura Y, et al. Transcription factor $Y Y 1$ contributes to tumor growth by stabilizing hypoxia factor HIF1alpha in a p53-independent manner. Cancer Res. 2013;73:1787-99.

67. Liu G, Zhou L, Zhang H, Chen R, Zhang Y, Li L, et al. Regulation of hepatic lipogenesis by the zinc finger protein Zbtb20. Nat Commun. 2017;8(1): 14824. https://doi.org/10.1038/ncomms14824.

68. Chen T, You Y, Jiang H, Wang ZZ. Epithelial-mesenchymal transition (EMT): a biological process in the development, stem cell differentiation, and tumorigenesis. J Cell Physiol. 2017;232:3261-72.

69. Mani SA, Guo W, Liao MJ, Eaton EN, Ayyanan A, Zhou AY, et al. The epithelial-mesenchymal transition generates cells with properties of stem cells. Cell. 2008;133:704-15.

70. Goossens S, Janzen V, Bartunkova S, Yokomizo T, Drogat B, Crisan M, et al. The EMT regulator Zeb2/Sip1 is essential for murine embryonic hematopoietic stem/progenitor cell differentiation and mobilization. Blood. 2011;117:5620-30

71. Seuntjens E, Nityanandam A, Miquelajauregui A, Debruyn J, Stryjewska A, Goebbels S, et al. Sip1 regulates sequential fate decisions by feedback signaling from postmitotic neurons to progenitors. Nat Neurosci. 2009; 12(11):1373-80. https://doi.org/10.1038/nn.2409.

72. Fardi M, Alivand M, Baradaran B, Farshdousti HM, Solali S. The crucial role of ZEB2: from development to epithelial-to-mesenchymal transition and cancer complexity. J Cell Physiol. 2019;234(9):14783-99. https://doi.org/10.1 002/jcp.28277.

73. Comijn J, Berx G, Vermassen P, Verschueren K, van Grunsven L, Bruyneel E, et al. The two-handed $\mathrm{E}$ box binding zinc finger protein SIP1 downregulates E-cadherin and induces invasion. Mol Cell. 2001;7:1267-78. 
74. Takakura N, Watanabe T, Suenobu S, Yamada Y, Noda T, Ito Y, et al. A role for hematopoietic stem cells in promoting angiogenesis. Cell. 2000;102(2): 199-209. https://doi.org/10.1016/S0092-8674(00)00025-8.

75. Tang Y, Feinberg T, Keller ET, Li X, Weiss SJ. Snail/slug binding interactions with YAP/TAZ control skeletal stem cell self-renewal and differentiation. Nat Cell Biol. 2016;18:917-29.

76. Caja L, Tzavlaki K, Dadras MS, Tan E, Hatem G, Maturi NP, et al. Snail regulates BMP and TGF $\beta$ pathways to control the differentiation status of glioma-initiating cells. Oncogene. 2018;37(19):2515-31. https://doi.org/10.1 038/s41388-018-0136-0.

77. Carpenter S, Ricci EP, Mercier BC, Moore MJ, Fitzgerald KA. Posttranscriptional regulation of gene expression in innate immunity. Nat Rev Immunol. 2014;14:361-76.

78. Medzhitov R, Horng T. Transcriptional control of the inflammatory response. Nat Rev Immunol. 2009;9(10):692-703. https://doi.org/10.1038/nri2634.

79. Jin J, Zeng H, Schmid KW, Toetsch M, Uhlig S, Moroy T. The zinc finger protein Gfi1 acts upstream of TNF to attenuate endotoxin-mediated inflammatory responses in the lung. Eur J Immunol. 2006;36(2):421-30. https://doi.org/10.1002/eji.200535155.

80. Kawai T, Akira S. TLR signaling. Semin Immunol. 2007;19(1):24-32. https:// doi.org/10.1016/j.smim.2006.12.004

81. Zhong $X$, Feng $L, X u W H, W u X$, Ding YD, Zhou $Y$, et al. The zinc-finger protein ZFYVE1 modulates TLR3-mediated signaling by facilitating TLR3 ligand binding. Cell Mol Immunol. 2020;17(7):741-52. https://doi.org/10.103 8/s41423-019-0265-6

82. Fu M, Blackshear PJ. RNA-binding proteins in immune regulation: a focus on CCCH zinc finger proteins. Nat Rev Immunol. 2017;17:130-43.

83. Maeda K, Akira S. Regulation of mRNA stability by CCCH-type zinc-finger proteins in immune cells. Int Immunol. 2017;29(4):149-55. https://doi.org/1 0.1093/intimm/dxx015.

84. Carballo E, Lai WS, Blackshear PJ. Feedback inhibition of macrophage tumor necrosis factor-alpha production by tristetraprolin. Science. 1998;281:1001-5.

85. Vinuesa CG, Cook MC, Angelucci C, Athanasopoulos V, Rui L, Hill KM, et al. A RING-type ubiquitin ligase family member required to repress follicular helper T cells and autoimmunity. Nature. 2005;435:452-8.

86. Liang J, Wang J, Azfer A, Song W, Tromp G, Kolattukudy PE, et al. A novel $\mathrm{CCCH}$-zinc finger protein family regulates proinflammatory activation of macrophages. J Biol Chem. 2008;283:6337-46.

87. Matsushita K, Takeuchi O, Standley DM, Kumagai Y, Kawagoe T, Miyake T, et al. Zc3h12a is an RNase essential for controlling immune responses by regulating mRNA decay. Nature. 2009;458(7242):1185-90. https://doi.org/1 0.1038/nature07924.

88. Tanaka H, Arima Y, Kamimura D, Tanaka Y, Takahashi N, Uehata T, et al. Phosphorylation-dependent Regnase-1 release from endoplasmic reticulum is critical in IL-17 response. J Exp Med. 2019;216(6):1431-49. https://doi.org/1 0.1084/jem.20181078.

89. Hall TM. Multiple modes of RNA recognition by zinc finger proteins. Curr Opin Struct Biol. 2005;15(3):367-73. https://doi.org/10.1016/j.sbi.2005.04.004.

90. Zhang J, Wen X, Liu N, Li Y, Tang X, Wang Y, et al. Epigenetic mediated zinc finger protein 671 downregulation promotes cell proliferation and tumorigenicity in nasopharyngeal carcinoma by inhibiting cell cycle arrest. J Exp Clin Cancer Res. 2017;36:147.

91. Sun R, Xiang T, Tang J, Peng W, Luo J, Li L, et al. 19q13 KRAB zinc-finger protein ZNF471 activates MAPK10/JNK3 signaling but is frequently silenced by promoter CpG methylation in esophageal cancer. Theranostics. 2020; 10(5):2243-59. https://doi.org/10.7150/thno.35861.

92. Cao L, Wang S, Zhang Y, Wong K, Nakatsu G, Wang X, et al. Zinc-finger protein 471 suppresses gastric cancer through transcriptionally repressing downstream oncogenic PLS3 and TFAP2A. Oncogene. 2018;37:3601-16.

93. Huang C, Wu S, Li W, Herkilini A, Miyagishi M, Zhao H, et al. Zinc-finger protein p52-ZER6 accelerates colorectal cancer cell proliferation and tumour progression through promoting p53 ubiquitination. Ebiomedicine. 2019;48: 248-63

94. Li L, Liu X, He L, Yang J, Pei F, Li W, et al. ZNF516 suppresses EGFR by targeting the CtBP/LSD1/CoREST complex to chromatin. Nat Commun. 2017:8:691.

95. Li Y, Yang Q, Guan H, Shi B, Ji M, Hou P. ZNF677 suppresses Akt phosphorylation and tumorigenesis in thyroid Cancer. Cancer Res. 2018; 78(18):5216-28. https://doi.org/10.1158/0008-5472.CAN-18-0003.

96. Narita S, So A, Ettinger S, Hayashi N, Muramaki M, Fazli L, et al. GLI2 knockdown using an antisense oligonucleotide induces apoptosis and
Chemosensitizes cells to paclitaxel in androgen-independent prostate Cancer. Clin Cancer Res. 2008;14(18):5769-77. https://doi.org/10.1158/10780432.CCR-07-4282

97. Kudo K, Gavin E, Das S, Amable L, Shevde LA, Reed E. Inhibition of Gli1 results in altered C-Jun activation, inhibition of cisplatin-induced upregulation of ERCC1, XPD and XRCC1, and inhibition of platinum-DNA adduct repair. Oncogene. 2012;31(44):4718-24. https://doi.org/10.1038/onc.2 011.610.

98. Chen H, Hu L, Luo Z, Zhang J, Zhang C, Qiu B, et al. A20 suppresses hepatocellular carcinoma proliferation and metastasis through inhibition of Twist1 expression. Mol Cancer. 2015;14(1):186. https://doi.org/10.1186/s12 943-015-0454-6.

99. Liao L, Chen C, Li N, Lin L, Huang B, Chang Y, et al. Y-box binding Protein-1 promotes epithelial-mesenchymal transition in Sorafenib-resistant hepatocellular carcinoma cells. Int J Mol Sci. 2021;22:224.

100. Ng ZL, Siew J, Li J, Ji G, Huang M, Liao X, et al. PATZ1 (MAZR) co-occupies genomic sites with p53 and inhibits liver Cancer cell proliferation via regulating p27. Front Cell Dev Biol. 2021;9:586150.

101. Li Z, Lu X, Liu Y, Zhao J, Ma S, Yin H, et al. Gain of LINC00624 enhances liver Cancer progression by disrupting the histone deacetylase 6/tripartite motif containing 28/zinc finger protein 354C corepressor complex. Hepatology. 2021;73(5):1764-82. https://doi.org/10.1002/hep.31530.

102. Coulombe P, Nassar J, Peiffer I, Stanojcic S, Sterkers Y, Delamarre A, et al. The ORC ubiquitin ligase OBI1 promotes DNA replication origin firing. Nat Commun. 2019;10:2426.

103. Liang Y, Li Q, Chen K, Ni W, Zhan Z, Ye F, et al. Zinc finger protein 307 functions as a tumor-suppressor and inhibits cell proliferation by inducing apoptosis in hepatocellular carcinoma. Oncol Rep. 2017;38(4):2229-36. https://doi.org/10.3892/or.2017.5868.

104. Giannelli G, Koudelkova P, Dituri F, Mikulits W. Role of epithelial to mesenchymal transition in hepatocellular carcinoma. J Hepatol. 2016;65: 798-808.

105. Peukert K, Staller P, Schneider A, Carmichael G, Hänel F, Eilers M. An alternative pathway for gene regulation by Myc. EMBO J. 1997;16(18):567286. https://doi.org/10.1093/emboj/16.18.5672.

106. Wang $H, X u H$, Ma F, Zhan M, Yang X, Hua S, et al. Zinc finger protein 703 induces EMT and sorafenib resistance in hepatocellular carcinoma by transactivating CLDN4 expression. Cell Death Dis. 2020;11(4):225. https://doi. org/10.1038/s41419-020-2422-3.

107. Batlle E, Clevers H. Cancer stem cells revisited. Nat Med. 2017;23:1124-34.

108. Christofk HR, Vander Heiden MG, Wu N, Asara JM, Cantley LC. Pyruvate kinase $M 2$ is a phosphotyrosine-binding protein. Nature. 2008;452:181-6.

109. Giannelli G, Villa E, Lahn M. Transforming growth factor- $\beta$ as a therapeutic target in hepatocellular carcinoma. Cancer Res. 2014;74:1890-4.

110. He L, Fan X, Li Y, Chen M, Cui B, Chen G, et al. Overexpression of zinc finger protein 384 (ZNF 384), a poor prognostic predictor, promotes cell growth by upregulating the expression of cyclin D1 in hepatocellular carcinoma. Cell Death Dis. 2019;10(6):444. https://doi.org/10.1038/s41419-019-1681-3.

111. Karin M. NF- B as a critical link between inflammation and cancer. Cold Spring Harbor Perspect Biol. 2009;1:a000141.

112. Shahi $P$, Wang $C$, Lawson DA, Slorach EM, Lu A, Yu Y, et al. ZNF50 3/Zpo2 drives aggressive breast cancer progression by down-regulation of GATA3 expression. Proc Natl Acad Sci. 2017;114:3169-74.

113. Priem D, van Loo G, Bertrand MJM. A20 and cell death-driven inflammation. Trends Immunol. 2020;41(5):421-35. https://doi.org/10.1016/j.it.2020.03.001.

114. Lim S, Kaldis P. Cdks, cyclins and CKls: roles beyond cell cycle regulation. Development. 2013;140:3079-93.

115. Zhang L, Huo Q, Ge C, Zhao F, Zhou Q, Chen X, et al. ZNF143-mediated H3K9 Trimethylation upregulates CDC6 by activating MDIG in hepatocellular carcinoma. Cancer Res. 2020:80:2599-611.

116. Tchakarska G, Sola B. The double dealing of cyclin D1. Cell Cycle. 2020;19(2): 163-78. https://doi.org/10.1080/15384101.2019.1706903.

117. Peter ME. Apoptosis meets necrosis. Nature (London). 2011;471(7338):310-2. https://doi.org/10.1038/471310a.

118. Sessler T, Healy S, Samali A, Szegezdi E. Structural determinants of DISC function: new insights into death receptor-mediated apoptosis signalling. Pharmacol Ther. 2013;140:186-99.

119. Zheng X, Rumie Vittar NB, Gai X, Fernandez-Barrena MG, Moser CD, Hu C, et al. The transcription factor GLI1 mediates TGFb1 driven EMT in hepatocellular carcinoma via a SNAl1-dependent mechanism. PLoS One. 2012;7(11):e49581. 
120. Gai X, Tu K, Li C, Lu Z, Roberts LR, Zheng X. Histone acetyltransferase PCAF accelerates apoptosis by repressing a GLI1/BCL2/BAX axis in hepatocellular carcinoma. Cell Death Dis. 2015;6:e1712.

121. Cui J, Liu J, Fan L, Zhu Y, Zhou B, Wang Y, et al. A zinc finger family protein, ZNF263, promotes hepatocellular carcinoma resistance to apoptosis via activation of ER stress-dependent autophagy. Transl Oncol. 2020;13:100851.

122. Beck B, Blanpain C. Unravelling cancer stem cell potential. Nat Rev Cancer. 2013;13:727-38

123. Plaks V, Kong N, Werb Z. The cancer stem cell niche: how essential is the niche in regulating stemness of tumor cells. Cell Stem Cell. 2015;16(3):22538. https://doi.org/10.1016/j.stem.2015.02.015.

124. Rhie SK, Yao L, Luo Z, Witt H, Schreiner S, Guo Y, et al. ZFX acts as a transcriptional activator in multiple types of human tumors by binding downstream from transcription start sites at the majority of CpG island promoters. Genome Res. 2018;28:310-20.

125. Ni W, Perez AA, Schreiner S, Nicolet CM, Farnham PJ. Characterization of the ZFX family of transcription factors that bind downstream of the start site of CpG island promoters. Nucleic Acids Res. 2020;48(11):5986-6000. https://doi. org/10.1093/nar/gkaa384

126. Yu J, Hu K, Smuga-Otto K, Tian S, Stewart R, Slukvin II, et al. Human induced pluripotent stem cells free of vector and transgene sequences. Science. 2009;324(5928):797-801. https://doi.org/10.1126/science.1172482.

127. Lai KP, Chen J, He M, Ching AKK, Lau C, Lai PBS, et al. Overexpression of ZFX confers self-renewal and chemoresistance properties in hepatocellular carcinoma. Int J Cancer. 2014;135(8):1790-9. https://doi.org/10.1002/ijc.28819.

128. Wang C, Fu SY, Wang MD, Yu WB, Cui QS, Wang HR, et al. Zinc finger protein X-linked promotes expansion of EpCAM+ cancer stem-like cells in hepatocellular carcinoma. Mol Oncol. 2017;11:455-69.

129. Bahrami A, Majeed M, Sahebkar A. Curcumin: a potent agent to reverse epithelial-to-mesenchymal transition. Cell Oncol. 2019;42(4):405-21. https://doi.org/10.1007/s13402-019-00442-2.

130. Li LY, Yang JF, Rong F, Luo ZP, Hu S, Fang H, et al. ZEB1 serves an oncogenic role in the tumourigenesis of $\mathrm{HCC}$ by promoting cell proliferation, migration, and inhibiting apoptosis via Wnt/beta-catenin signaling pathway. Acta Pharmacol Sin. 2021;42(10):1676-89. https://doi. org/10.1038/s41401-020-00575-3.

131. Jiao W, Miyazaki K, Kitajima Y. Inverse correlation between E-cadherin and snail expression in hepatocellular carcinoma cell lines in vitro and in vivo. $\mathrm{Br}$ J Cancer. 2002;86(1):98-101. https://doi.org/10.1038/sj.bjc.6600017.

132. Winkler M, Staniczek T, Kürschner SW, Schmid CD, Schönhaber H, Cordero J, et al. Endothelial GATA4 controls liver fibrosis and regeneration by preventing a pathogenic switch in angiocrine signaling. J Hepatol. 2021; 74(2):380-93. https://doi.org/10.1016/j.jhep.2020.08.033.

133. Xiang Q, Zhou D, He X, Fan J, Tang J, Qiu Z, et al. The zinc finger protein GATA4 induces mesenchymal-to-epithelial transition and cellular senescence through the nuclear factor-kB pathway in hepatocellular carcinoma. J Gastroenterol Hepatol. 2019;34(12):2196-205. https://doi.org/1 $0.1111 /$ jgh. 14684.

134. Shahi P, Slorach EM, Wang C, Chou J, Lu A, Ruderisch A, et al. The transcriptional repressor ZNF503/Zeppo2 promotes mammary epithelial cell proliferation and enhances cell invasion. J Biol Chem. 2015;290:3803-13.

135. Yin G, Liu Z, Wang Y, Sun L, Wang L, Yao B, et al. ZNF503 accelerates aggressiveness of hepatocellular carcinoma cells by down-regulation of GATA3 expression and regulated by microRNA-495. Am J Transl Res. 2019; 11:3426-37.

136. Faubert B, Solmonson A, DeBerardinis RJ. Metabolic reprogramming and cancer progression. Science. 2020;368(6487):w5473. https://doi.org/10.1126/ science.aaw5473.

137. Vander Heiden MG, Cantley LC, Thompson CB. Understanding the Warburg effect: the metabolic requirements of cell proliferation. Science (Am Assoc Adv Sci). 2009;324:1029-33.

138. Jin X, Jin HR, Jung HS, Lee SJ, Lee J, Lee JJ. An atypical E3 ligase zinc finger protein 91 stabilizes and activates NF-kB-inducing kinase via Lys63-linked ubiquitination. J Biol Chem. 2010;285:30539-47.

139. Chen D, Wang Y, Lu R, Jiang $X$, Chen $X$, Meng N, et al. E3 ligase ZFP91 inhibits hepatocellular carcinoma metabolism reprogramming by regulating PKM splicing. Theranostics. 2020;10:8558-72.

140. Sun L, Suo C, Li S, Zhang H, Gao P. Metabolic reprogramming for cancer cells and their microenvironment: beyond the Warburg effect. Biochim Biophys Acta (BBA) - Rev Cancer. 2018;1870:51-66.
141. Ma A, Malynn BA. A20: linking a complex regulator of ubiquitylation to immunity and human disease. Nat Rev Immunol. 2012;12:774-85.

142. Catrysse L, Vereecke L, Beyaert R, van Loo G. A20 in inflammation and autoimmunity. Trends Immunol. 2014;35:22-31.

143. Feng Y, Zhang Y, Cai Y, Liu R, Lu M, Li T, et al. A20 targets PFKL and glycolysis to inhibit the progression of hepatocellular carcinoma. Cell Death Dis. 2020;11.

144. Lee J, Liu R, Li J, Zhang C, Wang Y, Cai Q, et al. Stabilization of phosphofructokinase 1 platelet isoform by AKT promotes tumorigenesis. Nat Commun. 2017;8(1):949. https://doi.org/10.1038/s41467-017-00906-9.

145. Kohnhorst $\mathrm{CL}$, Kyoung M, Jeon M, Schmitt DL, Kennedy EL, Ramirez J, et al. Identification of a multienzyme complex for glucose metabolism in living cells. J Biol Chem. 2017;292(22):9191-203. https://doi.org/10.1074/jbc.M117. 783050.

146. Ruf B, Heinrich B, Greten TF. Immunobiology and immunotherapy of HCC: spotlight on innate and innate-like immune cells. Cell Mol Immunol. 2021; 18(1):112-27. https://doi.org/10.1038/s41423-020-00572-w.

147. Zhang W, Zhangyuan G, Wang F, Jin K, Shen H, Zhang L, et al. The zinc finger protein Miz1 suppresses liver tumorigenesis by restricting hepatocyte-driven macrophage activation and inflammation. Immunity. 2021;54:1168-85.

148. Rousseau-Merck MF, Huebner K, Berger R, Thiesen HJ. Chromosomal localization of two human zinc finger protein genes, ZNF24 (KOX17) and ZNF29 (KOX26), to 18q12 and 17p13-p12, respectively. Genomics. 1991;9(1): 154-61. https://doi.org/10.1016/0888-7543(91)90233-5.

149. Harper J, Yan L, Loureiro RM, Wu I, Fang J, D'Amore PA, et al. Repression of vascular endothelial growth factor expression by the zinc finger transcription factor ZNF24. Cancer Res. 2007;67:8736-41.

150. Li J, Chen X, Gong X, Liu Y, Feng H, Qiu L, et al. A transcript profiling approach reveals the zinc finger transcription factor ZNF191 is a pleiotropic factor. BMC Genomics. 2009;10:241.

151. Liu G, Jiang S, Wang C, Jiang W, Liu Z, Liu C, et al. Zinc finger transcription factor 191, directly binding to beta-catenin promoter, promotes cell proliferation of hepatocellular carcinoma. Hepatology. 2012;55(6):1830-9. https://doi.org/10.1002/hep.25564.

152. Wu D, Liu G, Liu Y, Saiyin H, Wang C, Wei Z, et al. Zinc finger protein 191 inhibits hepatocellular carcinoma metastasis through discs large 1-mediated yes-associated protein inactivation. Hepatology. 2016;64:1148-62.

153. Liu Y, Wu D, Cheng H, Chen L, Zhang W, Zou L, et al. Wnt8B, transcriptionally regulated by ZNF191, promotes cell proliferation of hepatocellular carcinoma via Wnt signaling. Cancer Sci. 2021;112(2):629-40. https://doi.org/10.1111/cas.14738.

154. Wang Q, Tan YX, Ren YB, Dong LW, Xie ZF, Tang $L$, et al. Zinc finger protein ZBTB20 expression is increased in hepatocellular carcinoma and associated with poor prognosis. BMC Cancer. 2011;11(1):271. https://doi.org/10.1186/14 71-2407-11-271.

155. Yi PS, Wu B, Deng DW, Zhang GN, Li JS. Positive expression of ZNF689 indicates poor prognosis of hepatocellular carcinoma. Oncol Lett. 2018;16: 5122-30.

156. Sun $L$, Lin $Y$, Wang G, Zhang $L, H u ~ L, ~ L u ~ Z$. Correlation of zinc finger protein 2, a prognostic biomarker, with immune infiltrates in liver cancer. Biosci Rep. 2021;41(1). https://doi.org/10.1042/BSR20203115

\section{Publisher's Note}

Springer Nature remains neutral with regard to jurisdictional claims in published maps and institutional affiliations.

Ready to submit your research? Choose BMC and benefit from:

- fast, convenient online submission

- thorough peer review by experienced researchers in your field

- rapid publication on acceptance

- support for research data, including large and complex data types

- gold Open Access which fosters wider collaboration and increased citations

- maximum visibility for your research: over $100 \mathrm{M}$ website views per year

At $\mathrm{BMC}$, research is always in progress.

Learn more biomedcentral.com/submissions 